Onkologe $2018 \cdot 24: 826$

https://doi.org/10.1007/s00761-018-0464-2

Online publiziert: 12. September 2018

(c) Springer Medizin Verlag $\mathrm{GmbH}$, ein Teil von Springer Nature 2018

CrossMark

\section{Friederike Klein}

Wissenschaftliche Fachkommunikation, München, Deutschland

\section{Erratum zu: Neue Ergebnisse zur Immuntherapie hämatologischer Neoplasien}

\section{Kongress der European Hematology Association (EHA), 14.-17.06.2018 in Stockholm, Schweden}

\section{Erratum zu:}

Der Onkologe 2018

https://doi.org/10.1007/s00761-018-

0440-x

Im Untertitel der Originalpublikation stand versehentlich das Jahr 2017. Korrekt ist 23. Kongress der European Hematology Association (EHA), 14.-17.06.2018 in Stockholm, Schweden.

\section{Korrespondenzadresse}

\section{Friederike Klein}

Wissenschaftliche Fachkommunikation

Landwehrstr. 31, 80336 München, Deutschland

klein.friederike@mnet-online.de 